\title{
Bienertia Sinuspersici Leaves Extracts Accelerated Wound Healing in laboratory animals
}

\author{
Fatimah A. Jasim ${ }^{1, *}$ and Fatima Rafed Abass ${ }^{2}$ \\ \{fjasim119@gmail.com ${ }^{1}$; fatimarafed29@gmail.com ${ }^{2}$ \} \\ 1, ${ }^{*}$ Ph.D.in Histopathology; Biology Instructor, The Gifted Students' School- Basra, Ministry of \\ Education, Iraq; ${ }^{2}$ Fourth Stage, The Gifted Students' School- Basra, Iraq, 61030;
}

\begin{abstract}
The skin physiological differences between humans and animals, therefore, it is difficult to study wound healing procedures in animals. Moreover, there are raising for using animals for testing the therapeutic possessions of new compounds. Hence, the present study was conducted to establish an excisional and incisional model of skin wound healing to estimate the wound healing capability of Bienertia sinuspersici leaves, through histopathological examination by using 18 male rats divided into two types of the wound (incision and excision); each type contained 3 groups ( 3 rats each): Control Group: treated by cream without 5\% extract; Experimental Group (EG): treated by 5\% extract cream; Positive Control Group.: Treated with commercial cream. The result detected regeneration of the epidermis in the excision area was finished after 12 days post-surgery while in incision wounds, the epithelization interval for the positive control group, the negative control group (NCG), and the extract group were 10-12, 8-10, and 6-8 days, respectively. Increased in fibroblast as well as collagen fiber in an excision area for all groups with necrotic representation by deep eosinophilic staining area in some regions of control and positive groups was observed. Histopathological examination of the drug-treated groups' section revealed reducing the hair follicle and sweat glands in an excision area as well as in control groups but the B. sinuspersici showed some of the hair follicles appeared in this area.
\end{abstract}

Keywords: Accelerating wound healing; Bienertia sinuspersici; Cutaneous treatment; Excision wound; Incision wound.

\section{Introduction}

In many countries the plants used for the treatment, the plants have higher activity for the treatment so from the past people used plants for treatment (specially wound healing). Wound healing was important for the repair the damage of anatomical continuity of the skin. Many scholars reported the strengthen in repairing the wound tissues using extracts from herbal and isolated compounds in animal models. It was noticed that the methodology of repairing the is still not clear and detailed [1].

The use of plants for wounds and burns were explored by many medical physicians. Through multiple mechanisms, herbal compounds stimulated healing and redevelopment of the lost tissue. It is approved that the herbal supports to halt the bleeding from new wounds, obstruct microbial growth, and increase the rate of healing wounds [2]. These phytomedicines are not only inexpensive and available but also harmless, different parts of plants have used for wound healing recording due active components from the antimicrobial and nutritional [3].

Population rise, an insufficient supply of medicines, a large fee of cure, side influences, and medicine impedance have caused to raise the cost of plant materials as the main sources of treatment 
to many human illnesses $[4,5]$. This is a fact that the dependency on the plants and its extracts towards health concern [6].

Bienertia is a leafy plant of Chenomodiaceae, characterized by broad, rectangular leaves. Some leaves are wider when they are old. They are light green, with height about 10 to $60 \mathrm{~cm}$ and branches are removed from the primary trunk. Bienertia grows near the beaches and have high salt tolerance and grows in sandy land. Bienertia are green throughout the summer and their leaves are succulent and the water evaporates during its time, and the camels are acidified. It blooms between September and November and in the beginning, it looks like small yellow flowers [7].

According to the Wound Healing Society, wounds can be defined as physical damages that result in a slot or breakdown of the skin that causes disorder in the normal skin function and anatomy, since epithelial tissues are widespread throughout the body [8]. There are several factors controlled by a complex wound healing process that may accelerate or affect the process of wound healing activity. Once a wound occurs, the tissues are capable to heal through the mechanism of regeneration or repairing, a regeneration process followed by interchanging the damaged tissues with the same cells and more partial to healing [9]. Regeneration of human tissues appears to have their own limitations, epithelial tissue; liver and nerve cell have their own limit in regeneration.

Wounds are inescapable events in life. Wounds may increase due to physical, chemical or microbial actions, while healing is a permanent mechanism and preform an effort to keep the normal anatomical arrangement and function. Wound healing is a progression by which tissue revival passes. The organization and treatment of wounds are one of the immense potentials in plants and their extracts. These components motivation and restoration, healing of the absent tissue by various mechanisms as natural mediators [10]. This study aimed to evaluate the wound healing capacity of Bienertia sinuspersici leaves through histopathological examination.

\section{Materials and Methods}

\subsection{Extraction and Cream Formation}

The plant collected from Al Faw, Iraq in 2018. The leaves were washed and dried for the extraction according to Shwaish' procedure [11] than the formation of the cream was prepared as explained in Muthukumarasamy report [12] then storage within $4^{\circ} \mathrm{C}$ until used in the experiment.

\subsection{Experiment Design}

Eighteen male rats were used which divided into two types of the wound, included both wound types (incision and excision). Each of them took three groups (3 animals each): Experimental Group: treated with 5\% extract cream, NCG: treated with a simple cream base, and Positive Control Group: treated with commercial silver sulfadiazine $(0.01 \%)$ cream (Dr. Reddy's laboratories LA, LLC, USA). Wounds were created, by adopting the procedure where rats anesthetized by injection of $16.5 \mathrm{mg} / \mathrm{Kg}$ Xylazine and $112.5 \mathrm{mg} / \mathrm{Kg}$ Ketamine and wound area were sterilized with $10 \%$ solution of povidone-iodine and depleted using a razor for creating the incision wound model, a 3 $\mathrm{cm}$ long paravertebral incision made through the entire skin thickness laterally of the vertebral column of the betrayers for each edge of the wound.

After sewing, wound parts could not be integrated and mixed together. For erasure wounds, a recognized advice of $1 \mathrm{~cm}^{2}$ total area will be used to erase in the dorsal inter-scapular area for biopsy punch for which the erasure wounds might be left open to the air [13,15]. Creams were applied to sterilize with $10 \%$ solution of povidone-iodine, and by employing a soft cotton pad [11]. 


\subsection{Histopathological Examination:}

For light microscopic examination, skin tissues from each group were collected and fixed with buffered formalin for $24 \mathrm{~h}$ then wished. The specimens are dehydrated in ascending grades of ethanol $(70 \%, 80 \%, 90 \%, 100 \%, 100 \%)$, cleared in chloroform, and embedded in paraffin wax. The sections of 5-7 $\mu \mathrm{m}$ in thickness were contemporized and stained with Haematoxylin and Eosin and Van Geison [16] and then histopathological examination under light microscopy was done by using an imaging microscope (Leica, Switzerland).

\section{Results}

The regeneration of the epidermis in the excision area was terminated after 12 days postoperating theater while in incision wounds, the epithelization period in the experiment, positive, and NCG were 6-8, and 8-10, 10-12 days, respectively. In the samples, the differentiation process of keratinocytes was confirmed by the normal process of keratinization. The keratinized squamous epithelia appeared thinner in drug-treated sections while in $B$. sinuspersici treated groups it consisted of 5-6 layers (fig.1 b) 3-4 layers in drug-treated (fig. 1 b) and 4-5 layers in the control groups; with increasing in angiogenesis in addition to that collagen bundles density increased in an incision area (fig. 2 a, b, c); as well as collagen fiber in an excision area for all groups with collagen fiber necrotic representatives by deep eosinophilic staining area in some region which was more in control and drug-treated groups compared with that in B. sinuspersici extract-treated group (fig.1, a,b,c). Fibroblast was increased compared with fibrocyte in $B$. sinuspersici extract compared with control and drug-treated groups (figs.1,2. b) excision section revealed thickness in the stratum corneum layers in extract treated groups compared with control and drug-treated groups (fig. 2). Moreover, the collagen organizing into newly formed fibrils was observed (figs. 1,2), thus the scar was created.

Histopathological examination detected that keratinized squamous epithelia thinner in drugtreated sections. Several hair follicles with sebaceous glands detected in the region beside the excision area especially in $B$. sinuspersici extract treated groups. In addition to the proliferation of melanocyte increased in plant extract treated (as showed in figure 3-c) compared with other groups. Beneath the dermis was observed at the beginning of neo-angiogenesis in drug and extract-treated groups (fig. 3-a). The numeral of fibroblasts slightly raised in the dermis close to the wounded area, collagen fiber density increased in this area while collagen fiber necrotic which represents by deeply eosinophilic staining area in some region of a drug-treated group (fig. 4). While the examination of the section treated with drug-treated groups revealed reducing of a hair follicle and sweat glands in an excision area as well as in control groups. 


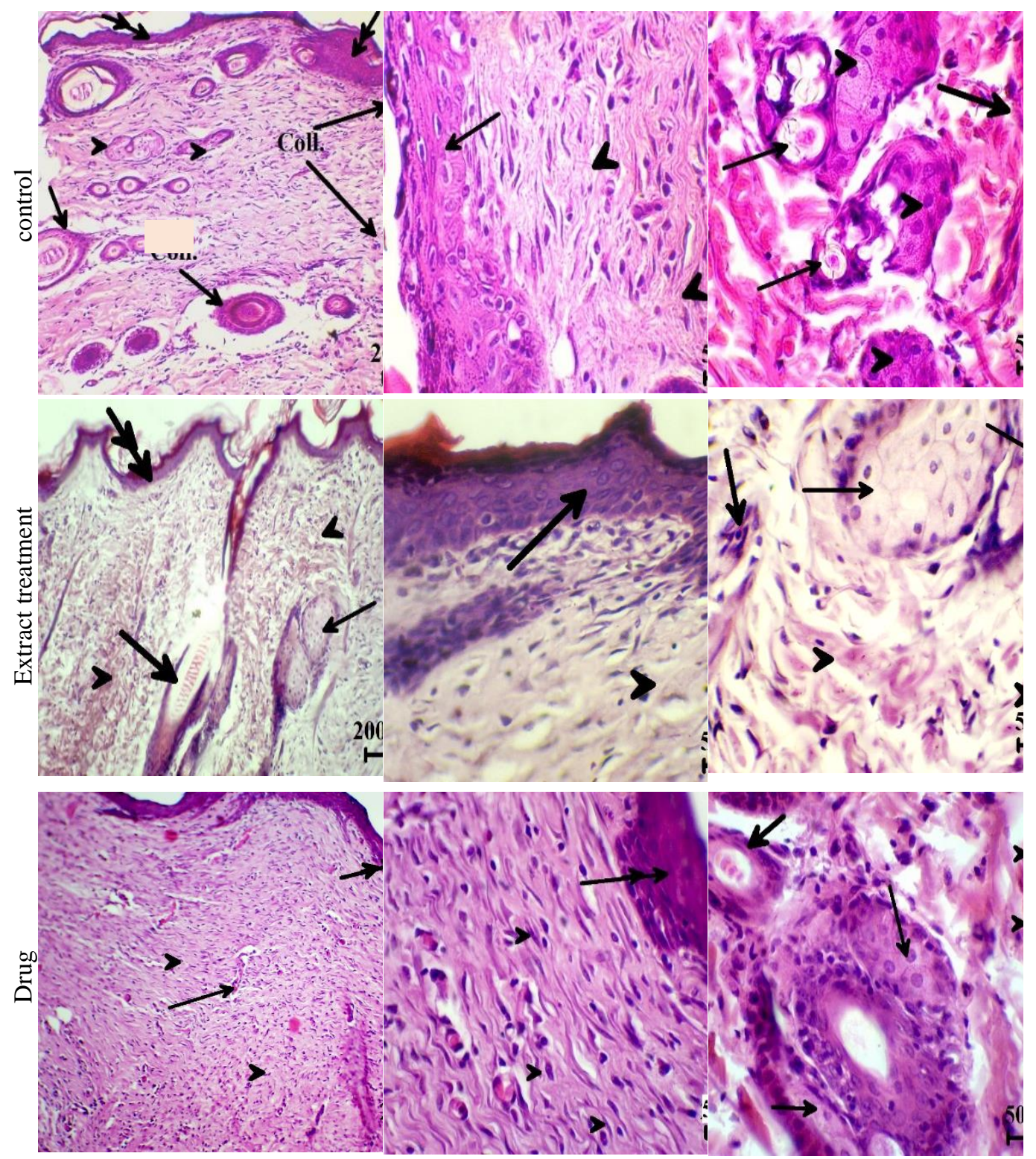

Fig. 1. Histopathological examination of the excision section in control, plant extract, and drug-treated section showed the plant extract improved excision wound healing. Fibroblast (heads arrow) detected in the wound healing area as well as some of the hair follicles (thick arrow). Decreasing in stratified squamous epithelial (double arrows) in a drug-treated group compared with other groups. H\&E stain. 

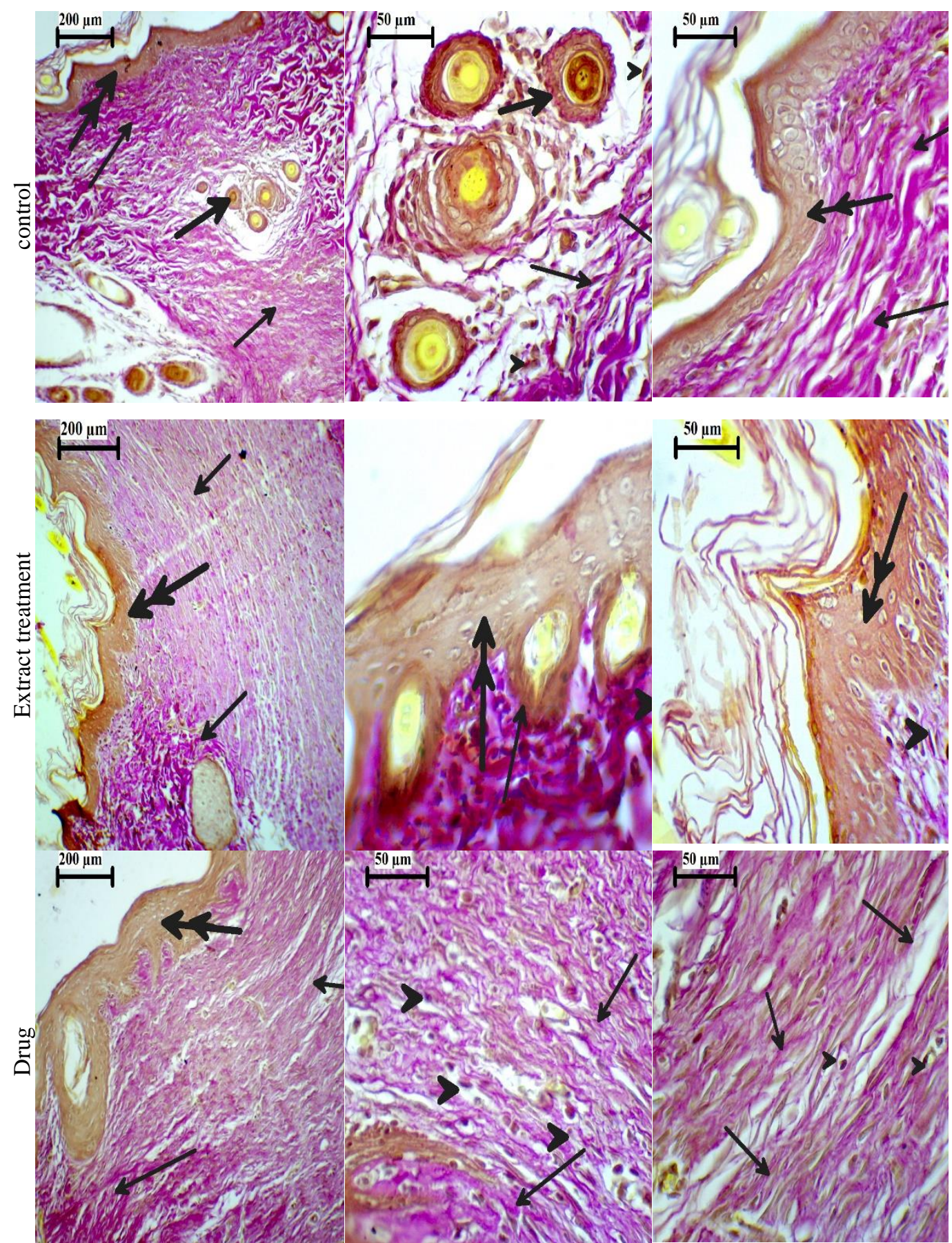

Fig. 2. Histopathological examination of the excision section in control, plant extract and drug-treated section showed an increase in collagen bundles (thin arrows) and fibroblast (heads arrow) in the wound healing area as well as some of the hair follicles (thick arrow). Increasing in stratified squamous epithelial (double arrows) in an extract-treated group compared with other groups. Van Gesion stain. 
A
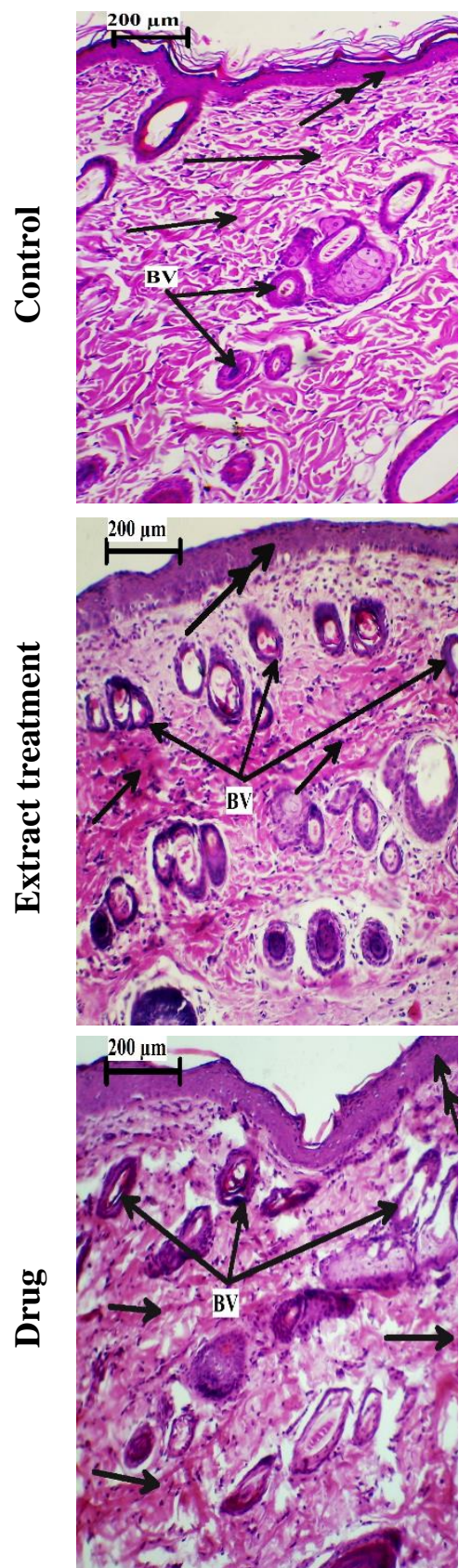

Fig. 3. Histopathological examination of the incision section in control, plant extract and drug-treated sections, A, B showed angiogenesis (BV: thick arrows), fibroblasts (heads arrow) and collagen bundles (thin arrows) were raised in the wound area with necrosis in drug-treated group. Stratified squamous epithelial (double arrows) thickness was increased in the extract-treated group compared with the others. $\mathrm{C}$ showed hyperplasia in the sebaceous glands in the drug-treated group compared with extract and control groups. H\&E stain. 

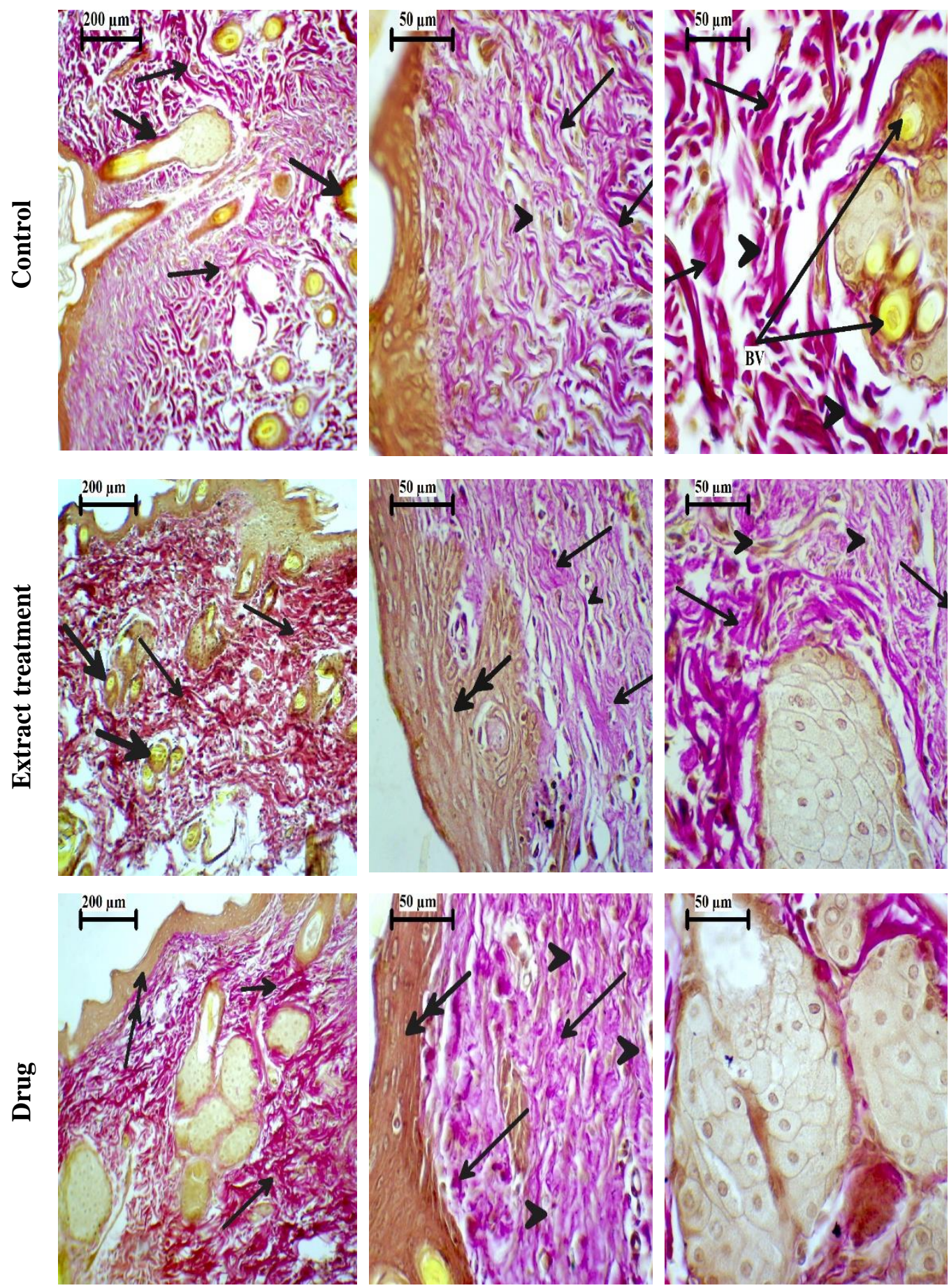

Fig. 4. Histopathological examination of the incision section in control, plant extract, and drug-treated section showed an increase in collagen bundles and fibroblasts in the wound healing area. Van Gesion stain. 


\section{Discussion}

In the present paper, we report the wound healing potential of Bienertia sinuspersici leaves through histopathological examination. We observed that the regeneration of the epidermis in the excision area was finished after 12 days, there is a different epithelized period from one group to another and differences observed in the layers of keratinized squamous epithelia. Also, the excision section detected thickness in stratum corneum layers in extract treated groups compared with control and drug-treated groups. Show increasing in fibroblast as well as collagen fiber in an excision area for whole groups. Several hair follicles appeared beside the excision area, especially in $B$. sinuspersici extract treated groups. Additionally, the increase in fibroblast compared with fibrocyte in $B$. sinuspersici extract compared with control and drug-treated groups due to fibroblast function in wound healing in combination with regenerating vascular endothelial cells. In cutaneous wound healing, skin cells travel from the wound ends into the wound to repair skin integrity [17]. In improver to the proliferation of melanocyte increased in plant extract treated that means in that respect are many glands do active work after wound healing. Skin wound healing involves inflammation, proliferation, and maturation. The inflammation, represents the defense system of the tissue, fighting the microbial contaminations [18]. The delay in healing tissues could be caused by long time of the inflammatory. This can be improved by applying the anti-inflammatory to to reduce the healing period [19].

The wound healing activity involves hemostasis, vascular response, inflammatory phase, proliferation, and development [20]. During wound healing, fundamental forces imposed by myofibroblasts and fibroblasts are responsible for a contraction process which stimulate by dermal cell proliferation and aggregation [21]. The ethanolic extract of Bienertia sinuspersici leaves increased cellular proliferation and collagen synthesis at the lesion site as shown by the increment in total collagen contents. Various natural products [22] herbal products, which are composed of active rules, such as alkaloids and flavonoids [23] and biomolecules [24] have been reported to boost the process of wound healing.

The preliminary phytochemical analysis of the ethanolic extract of Bienertia sinuspersici leaves revealed it contains alkaloids, flavonoids, glycosides, carbohydrates, tannins, and phenol [12]. In the report, ethanol was selected for its ability to distinguish the parts of the plant as mostly indicated in $[25,12]$. Such as flavonoids reduces the rate of lipid peroxidation by lowering the onset of cell necrosis but improving vascularity [26]. Terpenoids and flavonoids are also known to stimulate the wound- healing progression mostly due to their astringent and antimicrobial property, which seems to be responsible for wound shrinkage and raised the rate of epithelialization [27-30]. Lastly collagen is investigated into healing wounds that directly linked to weakness and integrity to tissue matrix.

\section{Conclusion}

Bienertia sinuspersici leaves have the potential to accelerate wound healing through decreased inflammation and regeneration by increased proliferation of fibroblast in the dermis layer. The outcomes of this work proposes pharmacological treatment suggestions in supporting the use of Bienertia sinuspersici leaves for the curing of wounds in many areas along with Al-Arab Golf. More subjects are needed for finding out which compound has the most effect accelerated the wound repair.

Acknowledgments: The authors would like to thank the Biology Department- the University of Basrah for their help during our experiment. 


\section{References}

[1] Sasidharan, S., Logeswaran, S., \& Latha, L. Y.; Wound healing activity of Elaeis guineensis leaf extract ointment. International Journal of Molecular Sciences, 13(1), 336-347 (2012).

[2] Kumar B, Vijayakumar M, Govindarajan R, \& Pushpangadan P, J.; Ethnopharmacological approaches to wound healing-Exploring medicinal plants of India, 114: 103-113 (2007).

[3] Okoli, C. O., Akah, P. A., \& Okoli, A. S.; Potentials of leaves of Aspilia africana (Compositae) in wound care: An experimental evaluation. BMC Complementary and Alternative Medicine, 7(24), 1-7 (2007).

[4] Yogayata, S.P., \& Vijay, D.W.; Herbal medicines and nutritional supplements used in the treatment of Glaucoma. Res J Pharm Biol Chem Sci. 3:331-9 (2012)

[5] Sundaram R, Jacob I . S, Suganthi P.; In vitro antiplasmodial activity of ethanolic extracts of South Indian medicinal plants against Plasmodium falciparum. Asian Pac J Trop Dis.;2:180-3 (2012)

[6] Yogisha, S. \& Raveesha, K.A.; In vitro antibacterial effect of selected medicinal plant extracts. J Nat Prod. ;2:64-9 (2009)

[7] Akhani, H., Barroca, J., Koteeva, N., Voznesenskaya, E., Franceschi, V., Edwards, G., Ghaffari S.M. \& Ziegler, H.; Bienertia sinuspersici (Chenopodiaceae): A New Species from Southwest Asia and Discovery of a Third Terrestrial C4 Plant Without Kranz Anatomy. Systematic Botany, 30(2), 290-301 (2005).

[8] Strodtbeck, F.; Physiology of wound healing, Newborn Infant Nurs. Rev, 1, 43-45, (2001)

[9] Nilugal, K. C., Fattepur, S., Asmani, M. F., Abdullah, I., Yong, V. A., \& Ugandar, R. E.; Wound Healing Activity of ethanolic extract of Scutellaria barbata D . Don ( Lamiaceae ) leaves extract in excision and burn wound models. Der Pharmacia Lettre, 9(12), 1-15 (2017).

[10] Alam, G., Singh, M. P., \& Singh, A.; Wound healing potential of some medicinal plants. International Journal of Pharmaceutical Sciences Review and Research, 9(1), 136-145 (2011).

[11] Shwaish, Z. T., Al-Imarah, J. F. \& Jasim A.F.; Wound Healing Capacity, Antibacterial Activity, and GCMS Analysis of Bienertia sinuspersici Leaves Extract. J. Phys.: Conf. Ser. 1294-062056 (2019).

[12] Muthukumarasamy R, Nur Ain Najihah Mohd Ideris. Formulation and evaluation of antioxidant cream containing methanolic extract of Piper betel leaves. International Journal of Pharma and Bio Sciences, 7(4) (2016)

[13] Nayak, B. S., Kanhai, J., Milne, D. M., Pereira, L. P., \& Swanston, W. H.; Experimental evaluation of ethanolic extract of carapa guianensis L. leaf for its wound healing activity using three wound models. Evidence-Based Complementary and Alternative Medicine, 2011, 1-6 (2011).

[14] Murphy, P.S. \& Evans, G.R.D. Advances in Wound Healing: A Review of Current Wound Healing Products. Plastic Surgery International.;2012:1-8 (2012).

[15] Pawar, R., Chaurasiya, P., Rajak, H., Singour, P., Toppo, F., \& Jain, A.; Wound healing activity of Sida cordifolia Linn. in rats. Indian Journal of Pharmacology, 45(5), 474 (2013).

[16] Drury, R.A.B., Wallington, E.A., \& Carmeron Sir R.; Carleton's histological technique. $4^{\text {th }}$ ed. London:Oxford University Press.129-33 (1967)

[17] Grada, A., Otero-Vinas, M., Prieto-Castrillo, F., Obagi, Z., \& Falanga, V.; Research Techniques Made Simple: Analysis of Collective Cell Migration Using the Wound Healing Assay. Journal of Investigative Dermatology, 137(2), e11-e16 (2017).

[18] Bowler, P.G., Duerden, B.I., \& Armstrong, D.G.; Wound microbiology and associated approaches to wound management. Clin Microbiol Rev., 14:244-69 (2001).

[19]Bjamsholt, T., Kirketerp-Moller, K., Jensen, P.O., Madsen, K.G., Phipps, R., Krogfelt, K., Med, N.H. \& Techn, M.G.; Why chronic wounds will not heal: A novel hypothesis. Wound Repair Regen.16:2-10 (2008).

[20] Emele, F.E., Izomoh, M.I., \& Alufohia, E.; Microorganisms associated with wound infections in Ekpoma, Nigeria. West. Afr. J. Med.; 18:97-100 (1999)

[21] Monaco, JL., \& Lawrence, T.; Acute Wound Healing, An Overview. Clinics in Plastic Surgery, 30:1-12 (2008)

[22] Fournier, R. \& Pie, G. E.; Skin tensile strength. Journal of Medical Engineering \&Technology, 24(6), $277-280$ (2000).

[23] Suguna, L., Chandrakasan, G., \&Joseph, K.T.; Influence of honey on biochemical and biophysical parameters of wounds in rats. J Clin Biochem Nutr;14:91 (1999).

[24] Sharma, S.P., Aithal, K.S., Srinivasn, K.K., Udupa, A.L., Kumar, V.,\& Kulkarni, D.R.; Antiinflammatory and wound healing activities of the crude alcoholic extracts and flavonoids of Vitex leucoxylon.

Fitoterapia; 61:263 (1990) 
[25] Chitra, P., Suguna, L.,\& Chandrakasan, G.; Influence of arginine wound healing in rats. J Clin Biochem Nutr;18:111 (1995)

[26] Thakur, R.; Jain, N.; Pathak, R.; \& Sandhu, S.S.; Practices in Wound Healing Studies of Plants. EvidenceBased Complementary and Alternative Medicine, 2011, 1-17, (2011)

[27] Olukemi OA, Sofidiya MO, Aderonke TS, Ajose I, Onalo M, Shauib B.; Annals of Biol. Res, 3(4): 16831789 (2012), Cited by (Barku et al. 2013).

[28] Tsuchiya, H., Sato, M., Miyazaki, T., Fujiwara, S., Tanigaki, S., \& Ohyama, M. J.; Comparative study on the antibacterial activity of phytochemical flavanones against methicillin-resistant Staphylococcus aureus Ethnopharmacol, , 50:27-34 (1996).

[29] Kumar, S., Kumar, A., Mishra, A., Singh, N., \& Ddwivedi, K. N.; Pharmacognostical studies, phytochemical screening and thin layer chromatography ( TLC ) profile of seed, seed coat and leaves of ingudi ( Balanites aegyptiaca ( linn .) Delile ) with special reference to. International Journal of Research and Analytical Reviews, 6(1), 434-442 (2019). Cited by Barku et al. 2013

[30] Barku, V. Y. A., Boye, A., \& Ayaba, S.; Phytochemical screening and assessment of wound healing activity of the leaves of Anogeissus leiocarpus. European Journal of Experimental Biology, 3(4), 18-25 (2013). 